\title{
Effectiveness of crystalline admixtures and lime/cement microcapsules in engineered self-healing capacity of lime mortars
}

\author{
C. De Nardi ${ }^{1 *}$, S. Bullo ${ }^{1}$, L. Ferrara ${ }^{2}$, L. Ronchin ${ }^{3}$, A. Vavasori ${ }^{3}$ \\ 1 Università IUAV di Venezia, DACC - Venezia, Italy , cristinadenardi@iuav.it \\ ${ }^{2}$ Politecnico di Milano, DICA - Milano, Italy, \\ ${ }^{3}$ Università Cà Foscari Venezia, DSMN - Venezia, Italy
}

\begin{abstract}
Recently, the use of lime mortars in the restoration of historic buildings has found a renewed interest because they can guarantee the required mechanical, chemical and physical compatibility with the existing substrate. Spontaneous occurrence of self-healing phenomena in lime-based mortars is well known; the possibility of engineering the selfhealing capacity, through tailored additions, is therefore of the utmost interest with the aim of enhancing the durability of the building masonry restoration works. This work proposes a system for the evaluation of the self-healing capacity with reference to traditional and advanced lime mortars.
\end{abstract}

The autogenous healing capacity of a reference lime mortar has been first of all evaluated.

Then, the possibility of engineering the aforementioned capacity has also assessed, through both commercial crystalline admixtures and tailored encapsulated additives. These should work according to a twofold mechanism: first, the capsules envelope a core of lime mortar with purpose of making it inert during the hardening phase. Secondly, once the capsules rupture upon cracking and damage of the mortar, the reactive binder is released and undergoes a delayed hardening, which is responsible of the healing phenomena.

The results show that the mortar is able to heal micro-cracks; moreover, the addition of the crystalline admixture enhances this capacity. The different kinds of employed microcapsules were also able to induce a sensible self-healing, but they decrease the instantaneous compressive strength.

Keyword: self-healing; lime mortars; compressive strength; microcapsules.

\section{Introduction}

The increasing need for repairing and retrofitting a large number of heritage buildings and structures has motivated a likewise increasing interest for the design 
of advanced materials to be employed in the aforementioned actions.

As a matter of fact these materials, on the one hand, have to feature a high physical, chemical and mechanical compatibility with the existing subgrade [1]. On the other hand, they have to be able to provide a substantial improvement of the masonry unit behaviour, ever under severe mechanical and environmental actions, thus also contributing to delay or prevent any further degradation [2]. In view of this, the concept and design of new advanced materials to be employed for retrofitting and restoration of heritage buildings should be approached by "mimicking" the composition of original "historical" materials. Lime-based mortars - consisting of lime as a binder, fine aggregates (generally river or quarry sand) and water - have been used since ancient times in stone and brick masonry buildings, dating back to as early as $12.000 \mathrm{BC}$ in Palestine and Turkey [3],[4] and, through ancient Greek and the Roman Empire [5,6], have been continuously used almost without interruption so far.

In recent years, the use of lime-based mortars in retrofitting of existing heritage masonry buildings has been continuously increasing, right because they thoroughly satisfy the aforementioned compatibility with existing substrates [7]. As matter of fact, lime-based mortars also feature an autogenous healing capacity, because of the deposition in and across the cracks of crystals produced by delayed carbonation reactions [8].

The possibility of engineering this process with the addition of innovative constituents in traditional lime mortars, is therefore of the utmost interest. The aim is to obtain advanced "smart" lime mortars, which are able to enhance the durability of the whole building, while maintaining the authenticity of the render. Self-healing materials are a class of smart materials that feature the inborn capacity to self-repair a damage caused by mechanical stresses over time, without external intervention.

Many biological systems, such as skin and bones, inherently possess the functionality to heal, more or less autonomously, cracks and other forms of accidental damage.

In the last decade a continuously increasing research activity has been focused on self-healing construction, mostly cement based, materials.

In this framework RILEM Technical Committee 221-SHC Report [9] proposed a self-healing terminology based on the result of the action: "self-closing/self- 
sealing" or "self-healing"; and on the process of the action:

"autogenic/autogenous" and/or "autonomic/engineered" [10]. In the case of autogenic/autogeneous self-closing/self-sealing, own generic material constituent closes the cracks, whereas, in the case of autogenic/autogenous self-healing, own generic material constituent, besides sealing the cracks, is also able to restore its properties. On the other hand, in the case of autonomic/engineered self-closing, the sealing of the cracks is due to an engineered/tailored addition, which, if also recovery of the mechanical properties is achieved, results into autonomic/engineered self-healing.

It is worth remarking that several studies have regarded to self-healing capacity of lime-based mortars as a sort of bonus, mainly in old masonry constructions [7], but these properties have seldom been sought through an appropriate material design.

Lubelli et al. (2011) [11] highlighted that self-healing mechanisms in lime-based mortars consist of "dissolution, transport and re-precipitation of calcium compounds to heal the cracks". It was observed that the necessary condition for the occurrence of self-healing is the presence of a considerable quantity of free lime, coupled with a large amount of moisture in the wall.

This phenomenon can be explained through a progressive movement of free lime particles in the vicinity of the cracks: when the lime particles enter into contact with moisture, they react with it and the reaction products can fill the cracks. Along time, the newly deposited material could be able to reconstruct even completely the matrix through crack continuity.

Similarly to lime-based mortars, concrete has an autogenous self-healing capacity, caused by ongoing hydration of clinker minerals or by carbonation of calcium hydroxide $\left(\mathrm{Ca}(\mathrm{OH})_{2}\right)$. This phenomenon is anyway limited to small cracks, difficult to control and only effective when water is available. Nonetheless, concrete composition can be modified to undergo engineered crack healing, by means of several techniques, including, e.g., super absorbent polymers, shape memory alloys, biological approaches [12]-[13], crystalline admixtures [14] and expansive additions, encapsulated products, brittle tubes containing different crack healing agents [10].

In this paper, the results of a comparative study on autogenous and engineered self-healing capacity of lime mortars are presented. The self-healing capacity has 
been engineered through the use of commercially available crystalline admixtures, already studied in recent works [15-18], and by means of purposed - made encapsulated additions, the fabrication process of which will also be describe in detail.

These additions are designed as binder granules, protected by an impermeable coating, able to make them inert during setting and hardening phases. Then - in service condition, when an external stress is applied, the protective layer should rupture, releasing the reactive binder, which can thus undergo a delayed setting and hardening. The products of these reactions can thus be able to seal and/or heal the cracks created by the applied stress as above.

The experimental methodology for assessing the self-healing capacity is based on the analysis of the compressive strength recovery of specimens which have been pre-damaged up to a prescribed fraction of the material compressive strength, immersed in water for different scheduled times and then re-tested up to failure.

Preliminary results of this research, with reference to plain mortar and mortar with crystalline admixtures up to 42 days age, and instantaneous characterization (no healing) of mortar with capsules have been recently presented in conference proceedings [19]. In this paper a comprehensive view of the self-healing capacity of capsules added mortars will be provided together with evaluation of selfhealing capacity of plain and crystalline admixture mortar up to medium-long terms (more than six months).

It is author belief that only the analysis of the whole set of results, as herein presented, with main reference to the self-healing efficacy in medium-long term, can allow a clear understanding of the phenomenon, corroborating the partial conclusions to which short term results may lead.

\section{Materials}

A reference lime mortar was first of all produced with the aim of reproducing the composition and performance mortars in existing historical building. The mortar consists of natural hydraulic lime (NHL5) with the addition of calcium hydroxide $\left(\mathrm{Ca}(\mathrm{OH})_{2}\right)$. The composition of the mortar and the chemical constituents of the lime are respectively listed in Table $\mathbf{1}$ and $\mathbf{2}$.

Table 1. Mix designs of investigated lime mortars 
Table 2. Chemical analysis of the main components of the limes, percentages related to original dry material.

Besides the reference mortar, a second one containing a commercially available crystalline admixtures ( $3 \%$ by weight of lime) as well as four mixes containing tailored encapsulated binders have also been produced, as per composition also listed in Table 1.

\subsection{Crystalline admixtures}

The crystalline admixture employed in this paper has been already widely employed for engineering self-healing of concrete and cementitious composites [15]. The reader is referred to the cited works for details about its composition and morphological structures.

\subsection{Tailored encapsulated binders}

Four types of self-healing microcapsules have been produced and tested:

I_hydraulic lime-based, with an inorganic shell, (NHL5_NaF)

II_hydraulic lime-based, with an organic shell (NHL5_AM_AF)

III - IV_cement based, with two different types of organic shell (CEM_AM CEM_AF).

Acronyms reported in brackets show binder granule and coating type (NHL5: natural hydraulic lime; CEM: Portland cement 32.5 R; NaF: Sodium Fluoride; AM: maleic anhydride; AF: phthalic anhydride).

The Two different capsulate coatings also featured a different behaviour, which can also affect their effectiveness: as matter of fact while $\mathrm{NaF}$ features a brittle fracture (which may make it vulnerable also during the mixing phase), the organic shell composites feature a rather ductile failure.

Both organic and inorganic materials were prepared following procedures similar to those employed in the preparation of heterogeneous catalyst i.e. impregnation and/or precipitation of the coating material over the granule of binder.

For the inorganic synthesis of the protected binder particles, NHL5 was treated with an aqueous solution of $\mathrm{NaF}$ for 10 minutes under vigorous stirring and then left to rest. After $1 \mathrm{~h}$ the material, separated from the solution by centrifugation 
and wash with plenty of water, was finally dried at $120^{\circ} \mathrm{C}$ for $20 \mathrm{~h}$ and calcined at $450^{\circ}$ for $20 \mathrm{~h}$. In typical preparation, $250 \mathrm{~mL}$ of aqueous solution of $\mathrm{NaF}$ at $5 \%$ were mixed with $100 \mathrm{~g}$ of NHL5, then washed with about $1.5 \mathrm{~L}$ of water in order to remove the excess of fluoride and sodium ions.

For the synthesis of the organic protected binder particles, NHL5 or CEM were dispersed in dichloromethane under magnetic stirring. Then the desired amount of glycerol was added to the suspension, and stirred for $1 \mathrm{~h}$. Then maleic anhydride and/or phthalic anhydride were added to the slurry and stirring was continued for $3 \mathrm{~h}$. Finally, the solid was separated by centrifugation and washed with dichloromethane in order to remove the unreacted anhydride. In a typical preparation, $100 \mathrm{~g}$ of binder were dispersed in $250 \mathrm{~mL}$ of dichloromethane and about $5 \mathrm{~g}$ of glycerol were added dropwise. Then $100 \mathrm{~mL}$ solution of anhydride at $5 \%$ were added in 10 minutes. Evidences of polymer formation on binder surface was checked by infrared spectroscopy.

\section{Experimental programme and methodology}

The experimental programme has been structured as follow:

- for all the investigated mortars a first series of cube specimens $(50 \times 50 \times 50)$ $\mathrm{mm}^{3}$ was prepared with each of the investigated mortars according to WSDOT Test Method T813 [21].

Specimens were cured for 28 days in lab environment at $\mathrm{T}=23^{\circ} \mathrm{C} \pm 2^{\circ}$ and $\mathrm{RH}$ $50 \% \pm 4 \%$, was tested for compressive strength. At the same time, a second series of companion specimens was pre-cracked at $70 \%$ of compressive strength ( $70 \%$ $\mathrm{f}_{\mathrm{c}}$ ) determined as above and then cured in water for 14 days. At the end of the curing/conditioning period, specimens were re-tested for compressive strength up to failure. The self-healing was evaluated through the strength gain, with the respect to the pre-cracking stage, after the 14 days conditioning period. For each case, five specimens were tested: one for instantaneous compressive strength, two were immediately re-tested after pre-cracking and two were re-tested after 14 days in water.

- for the reference mortar and the mortar with crystalline admixture as well, investigation was extended also to include effects of exposure condition and time. After curing for 28 days in lab environment and pre-cracking at $70 \%$ of the compressive strength as above, specimens were cured in water or in lab 
environment for different times $(28,56,84,140 ?, 196$ days $)$ and re-tested for compressive strength as above. The strength gain, in case, was anyway compared with the performance of virgin companion samples undergoing the same history. For each mix, curing condition, damage level (pre-damaged or not) and curing time three specimens were tested and re-tested for compressive strength as above. All uniaxial compressive strength tests and pre-cracking tests as well, were performed under displacement control at a displacement rate equal to $0.2 \mathrm{~mm} / \mathrm{min}$ using a Galdabini Sun 20 testing machine.

\section{Experimental results and discussion}

\subsection{Mortar embedded with self-healing microcapsules}

Table 3 shows for all the investigated mixes the results of 28 days compressive strength, as well as the strength exhibited by pre-damaged specimens, retested to failure both immediately after the pre-damage and after 14 days curing in water.

Table 3. Test results of lime mortars with different types of self-healing microcapsules.

Experimental results show that the addition of the crystalline admixtures does not alter the instantaneous strength, while the all the microcapsules addition, acting as defects, induce a significant strength decrease.

Moreover, it can be observed that reloading specimens immediately after predamage yields to compressive strength values comparable to if not lower than the instantaneous strength ones.

Retesting pre-damaged specimens after 14 days in water has resulted in a moderate healing ( $3.37 \mathrm{vs} 3.23 \mathrm{~N} / \mathrm{mm}^{2}$ ) for the reference mortar and in an even higher healing capacity for the mortar with the crystalline admixtures (4.31 vs. $3.13 \mathrm{~N} / \mathrm{mm}^{2}$ ).

As for the capsules, the lime ones scantly produced any healing except for the addition of 6\% NH_AM_AF. On the other hand cement capsules produced more substantial healing.

In order to quantify the healing capacity through the measured recovery of compressive strength an index of healing was hence calculated as follows: 
ILR $=\frac{P_{\text {reload }}-P_{\text {pre-damage }}}{P_{\text {max instantaneous }}}$

Where $\left(\mathrm{P}_{\text {pre-damage }}=0.7 \mathrm{P}_{\text {instantaneous }}\right)$

The values of the index is plotted in Fig 1 for all the investigated mixes, confirming the aforementioned statement and providing quantitative evaluation of the self-healing capacity.

Fig 1. Strength change after instantaneous post-damage reloading and after postcuring/healing reloading

A deeper insight into the results is provided by TGA analysis of reference mortar and mortar containing the lime capsules in organic shell. The DSC/TGA measurements were carried out on a Linseis TGA 1000 from $40^{\circ} \mathrm{C}$ to $900^{\circ} \mathrm{C}$ with a ramp of temperature of $20^{\circ} \mathrm{C} / \mathrm{min}$, from $40^{\circ} \mathrm{C}$ to $900^{\circ} \mathrm{C}$.

For the reference mortar (Fig 2a), the TGA/DSC measurements highlight the weight loss typical of water desorption centred at $100^{\circ}-110^{\circ} \mathrm{C}$ together with that of de-carbonation which starts at $700^{\circ} \mathrm{C}$ and ends at $900^{\circ} \mathrm{C}$. In correspondence of the weight loss, there are two neat endothermic DSC peaks assigned to these reactions, both evident also for the mortar with the self-healing additive. In Fig. 2 (b) mortar with lime capsules shows a more complex profile of weight loss due to several processes occurring sequentially. It is evident the weight loss due to water desorption which starts at $100^{\circ} \mathrm{C}$, which anyway continues because of the presence of the organic substances desorbing continuously as the temperature increases. In fact, the polymeric film formed on the granule surface could have various degrees of polymerization and could decompose at several different temperatures, which justifies the continuous desorption. The rate of weight loss increases at $450^{\circ}-500^{\circ} \mathrm{C}$, temperature corresponding to $\mathrm{Ca}(\mathrm{OH})_{2}$ dehydration. In the range $700^{\circ}-900^{\circ} \mathrm{C}$ decarbonation is clearly observable. As regards the DSC measurements, it is noticeable the peak assigned to $\mathrm{Ca}(\mathrm{OH})_{2}$ dehydration centered at $500^{\circ} \mathrm{C}$ in perfect agreement with the weight loss above discussed [21].

Fig. 2 TGA/DSC measurements: (a) lime-based mortar, (b) lime-based mortar plus NHL5_AM_AF at $6 \%$ Run conditions (a) $65.12 \mathrm{mg}$, (b) $72.31 \mathrm{mg}$ heating rate $20^{\circ} \mathrm{C} / \mathrm{min}$. 
This is also confirmed by optical microscopy, performed, on phenolphthalein treated samples, to verify the presence of non-carbonated $\mathrm{Ca}(\mathrm{OH})_{2}$ particles on the mortar Optical microscopy observations were carried out with a Leitz Epi-lux at $40 \mathrm{X}$ equipped with a digital camera. In Fig 3 (a) which refers to the reference mortar, there are only small amounts of free $\mathrm{Ca}(\mathrm{OH})_{2}$, while in Fig 3 (b), which shows an image of moratar containing the NH5_AM_AF capsules, the fucsia color is more evident in agreement with a pronounced and homogeneous distribution of free $\mathrm{Ca}(\mathrm{OH})_{2}$ in the mortar. The latter is most likely responsible for the self-healing properties of the material.

Fig 3. Phenolphthalein test adsorption: (a) NHL5 mortar; (b) NHL5 mortar plus NHL5_AM_AF at 6\%

For mortar with cement capsules, the mechanism is clearly attributable to the delayed hydration of cement, which forms CSH crystals healing the cracks and filling the pores. Moreover the crystalline admixtures, on its hand, enhances as already well documented for the self-healing in cementitious matrices [15-18] the self-healing capacity thanks to its hydrophilic nature and its capacity to react with $\mathrm{Ca}(\mathrm{OH})_{2}$ (both present in the mortar from the biginning as well as produced by the ongoing lime hydration) and form C-S-H like crystals.

\subsection{Reference mortar and mortar with crystalline admixtures effect of exposure condition and time}

A second phase of the experimental campaign was carried out on longer cured mortar samples to characterize the development of the healing capacity over time. As recalled above, after 28 days, and after the pre-damage phase - always at $70 \%$ of the compressive strength - the samples were placed in water and exposed to lab environment and re-tested after 28-56-84-140-196 days, to determine the compressive strength recovery. Results are in Fig 4-5.

Fig. 4: Variation in compressive strength with age for reference mortar samples.

Fig. 5: Variation in compressive strength with age for reference mortar with crystalline additives samples

Reference mortar achieves its maximum strength at 28 days, and then a decrease is observed of about $20 \%$. It can be reasonably assumed that the laboratory dry 
climate causes drying shrinkage in the matrix, which generates micro-cracks responsible of the observed strength decrease over time.

Significantly, pre-damaged mortar specimens healed in laboratory environment, achieve similar strength as the undamaged ones exposed to the same conditions. On the other hand pre-damaged specimens immersed in water show a continuous increase of the performance, even if with a lower rate along time; the strength almost doubles with respect to reference undamaged specimens upon six months exposure.

The mortar with crystalline admixtures, as far as the development of its instantaneous strength over time, shows no significant difference with respect to the reference one, with the exception of a sort of strength regaining after aging $(\geq 7$ months).

This can be attributed to a delayed activity of the admixtures which, in dry conditions, needs longer time to show reactivity with the $\mathrm{Ca}(\mathrm{OH})_{2}$ produced by lime hydration.

As far as the healing performance of mortar containing the crystalline admixture, the following statements hold:

- pre-damaged specimens exposed to open air, achieve "recovered strength" at earlier ages higher than the one of virgin samples. This can be explained considering that because of the higher level of damage, larger amounts of crystalline admixtures may be exposed to outdoor environment and be thus able to capture outdoor moisture promoting faster reactions. This anyway also consumes their activity more rapidly, as witnessed by the fact that, upon longer exposure, the performance is absolutely similar to that of virgin specimens, in which, because of the lower damage which may only be due to some shrinkage, the activation of the additive activity is delayed, as explained above.

- specimens, immersed in water on other hand featured an outstanding strength recovery, almost doubling the strength of virgin specimens after just three months, after which the healing effects appears to be quite stable.

\subsection{Recovery of load bearing capacity}

The effects of the self-healing on the recovery of load bearing capacity once upon quantified by means of indices oh load recovery, calculated as in Eq (1) for investigated mixes and exposure conditions.

The following two indices of load recovery (ILR water; ILR air) have been 
defined and calculated referred to either the material virgin and post-conditioned.

Fig. 6 shows the trend of ILR (a) water and ILR air (b)

The evolution of the indices is shown in Fig 6. In detail:

- reference mortar cured in water, whose constituents may feature some delayed reactivity, shows a continuous increasing healing capacity along time, with a decreasing rate. As in cementitious binders, probably because of the natural hydraulic lime mortar constituents, the autogenous healing capacity can be mainly attributed to two processes: hydration of un-hydrated particles and dissolution and subsequent carbonation of $\mathrm{Ca}(\mathrm{OH})_{2}[11]$.

- reference mortar with crystalline additives, cured in water, features an immediately significant strength recovery; it could be reasonably assumed that admixtures react easily with water, sealing the cracks and fostering the recovery. As time goes by, the sealing proceeds and water can pass through the matrix to a lesser and lesser extent. The rate of performance recovery hence gradually slowers and stabilizes after six months.

In specimens cured in lab environment, ILR air shows a decreasing trend, but along time, the difference between mortar with and without admixtures slightly reduces, holding constant after five months. There is no doubt that under air, with low relative humidity, only a part of un-hydrated particles can moisturize and start a delayed hydration phase. In detail:

-reference mortar has always an index lower than 0.5 and tending to zero upon longer exposure. The mortar at later age will likely activate a lower and lower extent the delayed chemical reactions responsible of self-healing. - crystalline admixtures provide a significance enhancement of the healing capacity, initially quite higher and then stabilizing at values close to 0.3 . It can be reasonable assumed that this recovery of compressive strength is the result of a hydration process, which can self-heal pre-existing micro-cracks, by triggering the catalyst effect of the crystalline admixtures, on the surfaces of same cracks. 


\section{Conclusions}

In this work the effects of self-healing on the recovery of mechanical properties of lime-based mortars additioned with commercial admixtures and purpose-designed binder capsules has been experimentally evaluated by means of a tailored methodology based on the comparative analysis of pre-damaged/healed and virgin specimens.

Experimental results clearly show that the mortar, even without any addition, has some autogenous self-healing capacity, as witnessed by an about $20 \%$ strength recovery exhibited by specimens pre-damaged at 28 days and $70 \%$ of them compressive strength and cured for 14 days in water.

The presence of crystalline admixtures in the mortar matrix enhances the aforementioned self-healing capacity, due to the delayed hydration and carbonation of the lime as well as to the reaction of the admixtures with the $\mathrm{Ca}(\mathrm{OH})_{2}$, resulting from the lime hydration.

Moreover, the presence of crystalline additives speeds up the sealing of the cracks and the recovery of the mechanical properties. The effect of the crystalline admixture is even more evident for specimens exposed to open air, in which condition the autogenous healing capacity of the reference mortar is almost nil. The different types of investigated microcapsules, added to the reference mortar, were also able to induce a sensible self-healing with interesting compressive strength recovery, but actually, they significantly affected the instantaneous compressive strength, acting as inclusions. The analysis of microcapsules results, allows the following remarks to be highlighted:

- $\quad$ hydraulic lime and cement based microcapsules with organic shell provided the best self-healing capability. It can be reasonable assumed that the hydraulic components present in microcapsules react with the calcium hydroxide in the matrix to produce new hydration products, which can fill and bridge the cracks, as result from increased compressive strength, even if in the case of cement microcapsules may be questioned by conservators in heritage buildings. The ductile behaviour of the organic shell may have prevented them from rupturing during the mixing stage, hence keeping for longer curing time a large amount of reactive encapsulated binders.

The possibility to improve the self-healing capacity of lime-based mortars, which has been thoroughly highlighted in this study, increasing the durability and life 
cycle of the same mortar made of a masonry unit a whole, would represent an added value to their use in general and works restoration of heritage buildings, which deserve particular care.

\section{Acknowledgements}

The authors acknowledge the support of Penetron Italia and the kind availability of its CEA, MArch. Enrico Maria Gastaldo Brac, for providing the crystalline admixtures employed in this investigation.

The authors also thank the technicians of the Construction/Materials Science Laboratory (Labsco) University Iuav, for the support in performing experimental tests, and Mrs Beatrice Bordin, Ca' Foscari University, for the support in chemical experimental tests.

A special thanks to prof. Antonella Cecchi, IUAV University of Venice, for her insightful review of the manuscript and for her valuable comments in the concept of the investigation.

Conflict of Interest: the authors declare that they have no conflict of interest.

\section{References}

[1] Veiga MR, Velosa A; Magalhaes A (2009) Experimental applications of mortars with pozzolanic additions: Characterization and performance evaluation. Construction and Building Material: 23:318-327. doi:10.1016/j.conbuildmat.2007.12.003

[2] Veiga MR, Fragata A, Velosa A; Magalhaes A, Margalha G (2008), Substitution mortars for application in historical buildings exposed to the sea environment. Analysis of the viability of several types of compositions. In MEDACHS - Construction Heritage in Coastal and Marine Environments. Damage, Diagnostics, Maintenance and Rehabilitation, Lisbon. http://cathedral.Inec.pt/publicacoes/c14.pdf. Accessed 03 January 2017

[3] Kingery WE (1988) Introduction: Some aspects of the history of ceramic processing. In: Mackenzie, Ulrich, editors. Ultrastructure Processing of Advanced Ceramics. Ed Mackenzie and Ulrich, John Wiley, New York: pp 1-29.

[4] von Landsberg D (1992) The history of lime production and use from early times to the industrial revolution. Zement-Kalk-Gips 45:199-203.

[5] Abrams J W(1978) The masterbuilders. A history of structural and environmental design from ancient Egypt to the nineteenth century, Cowan HJ. Isis 69 3:452-453 doi: $10.1086 / 352089$

[6] Maravelaki-Kalaitzaki P, Bakolas A, Moropoulou A (2003). Physico-chemical study of Cretan ancient mortars. Cem Concr Res 33:651-661. doi: 10.1016/S00088846(02)01030-X 
[7] Lanas J. et al (2006) Mechanical properties of masonry repair dolomitic lime-based mortars, Cement and Concrete Research:36 (5):951-960.

http://dx.doi.org/10.1016/j.cemconres.2005.10.004

[8] Anderegg, FO (1942) Autogeneous healing in mortars containing lime. ASTM Bulletin $16: 22$.

[9] de Rooij M, Van Tittelboom K, De Belie N, Schlangen E. (2012) Self-healing Phenomena in Cement-Based Materials, State-of-the-Art Report of RILEM Technical Committee 221-SHC: Self-Healing Phenomena in Cement-Based Materials. ISBN 978-94-007-6624-2

[10] Mihashi H, Nishiwaki T (2012) Development of engineered self-healing and self repairing concrete, J. Adv. Concr. Technol 10 (5):170-184. doi:10.3151/jact.10.170

[11] Lubelli B, Nijland TG, van Hees RPJ (2011) Self-healing of lime-based mortars: microscopy observations on case studies. 13th Euroseminar on Microscopy Applied to Building Materials; Ljubljana, Slovenia.

[12] Jonkers HM (2011) Bacteria based self-healing concrete. Heron J 56 (1/2):1-11. http://heronjournal.nl/56-12/1.pdf Accessed 03 Jenuary 2017.

[13] Van Tittelboom K, De Belie N, De Muynck W (2010) Use of bacteria to repair cracks in concrete. Cementand Concrete Research:40: 157-166.

http://dx.doi.org/10.1016/j.cemconres.2009.08.025

[14] Wan Joa B, Sikandarb M, Balochb Z, Asad Khanb RM (2015) Effect of incorporation of self healing admixture (SHA) on physical and mechanical properties of mortars.

Journal of Ceramic Processing Research:16 (1):138-143.

http://jcpr.kbs-lab.co.kr/file/JCPR_vol.16_2015/JCPR16-S1/20.S22_138-143.pdf Accesed 10 Nov 2016

[15] Ferrara L, Krelani V, Carsana M (2014) A "fracture testing" based approach to assess crack healing of concrete with and without crystalline admixtures. Constr. Build. Mater 68:535-551. doi:10.1016/j.conbuildmat.2014.07.008

[16] Roig-Flores M, Moscato S, Serna P, Ferrara L (2015) Self-healing capability of concrete with crystalline admixtures in different environments, Construction and Building Materials 86:1-11. doi:10.1016/j.conbuildmat.2015.03.091

[17] Roig Flores, M, Pirritano, F, Serna Ros P and Ferrara L (2016) Effect of crystalline admixtures on the self-healing capability of early-age concrete studied by means of permeability and crack closing tests, Construction and Building Materials 114:447-457. doi: 10.1016/j.conbuildmat.2016.03.196

[18] Ferrara L, Krelani V, Moretti F (2016) On the use of crystalline admixtures in cement based construction materials: from porosity reducers to promoters of self healing", Smart Materials and Structures 25 (8): doi:10.1088/0964-1726/25/8/084002.

[19] De Nardi C, Bullo S, Cecchi A, Ferrara L (2016) Self healing capacity of advanced lime mortars. Advances in Materials and Processing Technologies, 2(3): 349-360

[20] UNI EN 1015-1 (2007). Metodi di prova per malte per opera murarie -

Determinazione della distribuzione granulometrica (mediante stacciatura).

[21] Sisomphon K, Copuroglu O, Koenders EAB (2012) Self-healing of surface cracks in mortars with expansive additive and crystalline additive. Cement Concr Compos 34:566574. http://dx.doi.org/10.1016/j.cemconcomp.2012.01.005

[22] WSDOT (2015) Test Method T 813, Field Method of Fabrication of 2 in (50 mm)

Cube Specimens for Compressive Strength Testing of Grouts and Mortars. 
http://www.wsdot.wa.gov/publications/manuals/fulltext/.../t813.pdf. Accessed 10 November 2016

[23] Villain G, Thiery M, Platret G (2007) Measurement methods of carbonation profiles in concrete: thermogravimetry, chemical analysis and gamma densimetry", Cement and Concrete Research 37:1182-1192. 


\section{Tables}

Table 1. Mix designs of investigated lime mortars

\begin{tabular}{l|c|c|c} 
Constituent & Reference mortar & $\begin{array}{c}\text { Reference mortar } \\
+ \text { crystalline } \\
\text { additives }\end{array}$ & $\begin{array}{c}\text { Reference mortar } \\
+ \text { S-H } \\
\text { microcapsules }\end{array}$ \\
\hline Slaked lime /dolomitic sand & $1 / 3$ & $1 / 3$ & $1 / 3$ \\
\hline Water /lime ratio (w/l) & $0.221 / \mathrm{kg}$ & $0.221 / \mathrm{kg}$ & $0.221 / \mathrm{kg}$ \\
\hline NHL5/ Ca(OH)2 ratio & $1 / 1$ & $1 / 1$ & $1 / 1$ \\
\hline Aero-crystalline additives & - & $\begin{array}{c}3 \% \text { by weight of } \\
\text { lime }\end{array}$ & - \\
\hline Self-healing microcapsules & - & - & $3-6 \%$ by weight of \\
lime
\end{tabular}

Table 2. Chemical analysis of the main components of the limes, percentages related to original dry material.

\begin{tabular}{l|c|c|c|c|c|c|c} 
Aggregate & $\mathbf{C a O}$ & $\mathbf{M g O}$ & $\mathbf{A l 2 O 3}$ & $\mathbf{K 2 O}$ & $\mathbf{N a 2 O}$ & $\mathbf{F e 2 O 3}$ & $\mathbf{S i O 2}$ \\
\hline NHL5 & $62 \%$ & $1 \%$ & $5 \%$ & $0,7 \%$ & $0,3 \%$ & $3,5 \%$ & $21 \%$
\end{tabular}

Table 3. Test results of lime mortars with different types of self-healing microcapsules.

\begin{tabular}{|c|c|c|c|c|}
\hline Mix design & $\begin{array}{l}\text { Testing } \\
\text { age } \\
\text { (days) }\end{array}$ & $\begin{array}{c}\text { Istantaneous } \\
\text { test } \\
\text { fc }\left(\mathrm{N} / \mathbf{m m}^{2}\right)\end{array}$ & $\begin{array}{c}\text { Test after } \\
70 \% \mathbf{f}_{\mathrm{c}} \text { and } \\
\text { immediate } \\
\text { reload } \\
\sigma \text { max } \\
\left(\mathrm{N} / \mathbf{m m}^{2}\right)\end{array}$ & $\begin{array}{c}\text { Test after } 70 \% \\
f_{c} \text { pre-cracking } \\
\text { and } 14 \text { days in } \\
\text { water } \\
\sigma_{\max }\left(\mathrm{N} / \mathrm{mm}^{2}\right)\end{array}$ \\
\hline Reference mortar & 28 & 3.23 & $2.21 \pm 0.05$ & $3.37 \pm 0.21$ \\
\hline Reference mortar $+3 \%$ & 28 & 3.13 & $2.93 \pm 0.02$ & $4.31 \pm 0.03$ \\
\hline I_6\% NHL5_NaF & 28 & 1.87 & $1.88 \pm 0.04$ & $2.01 \pm 0.06$ \\
\hline II_3\% NHL5_AM_AF & 28 & 1.93 & $1.89 \pm 0.10$ & $2.06 \pm 0.11$ \\
\hline II_6\% NHL5_AM_AF & 28 & 1.46 & $1.41 \pm 0.08$ & $1.98 \pm 0.15$ \\
\hline III_3\% CEM_AM & 28 & 1.97 & $1.71 \pm 0.42$ & $2.39 \pm 0.27$ \\
\hline III_6\% CEM_AM & 28 & 1.36 & $1.63 \pm 0.18$ & $2.65 \pm 0.08$ \\
\hline IV_3\% CEM_AF & 28 & 1.93 & $1.64 \pm 0.07$ & $3.12 \pm 0.20$ \\
\hline IV_6\% CEM_AF & 28 & 1.88 & - & $3.99 \pm 0.36$ \\
\hline
\end{tabular}




\section{Figures}

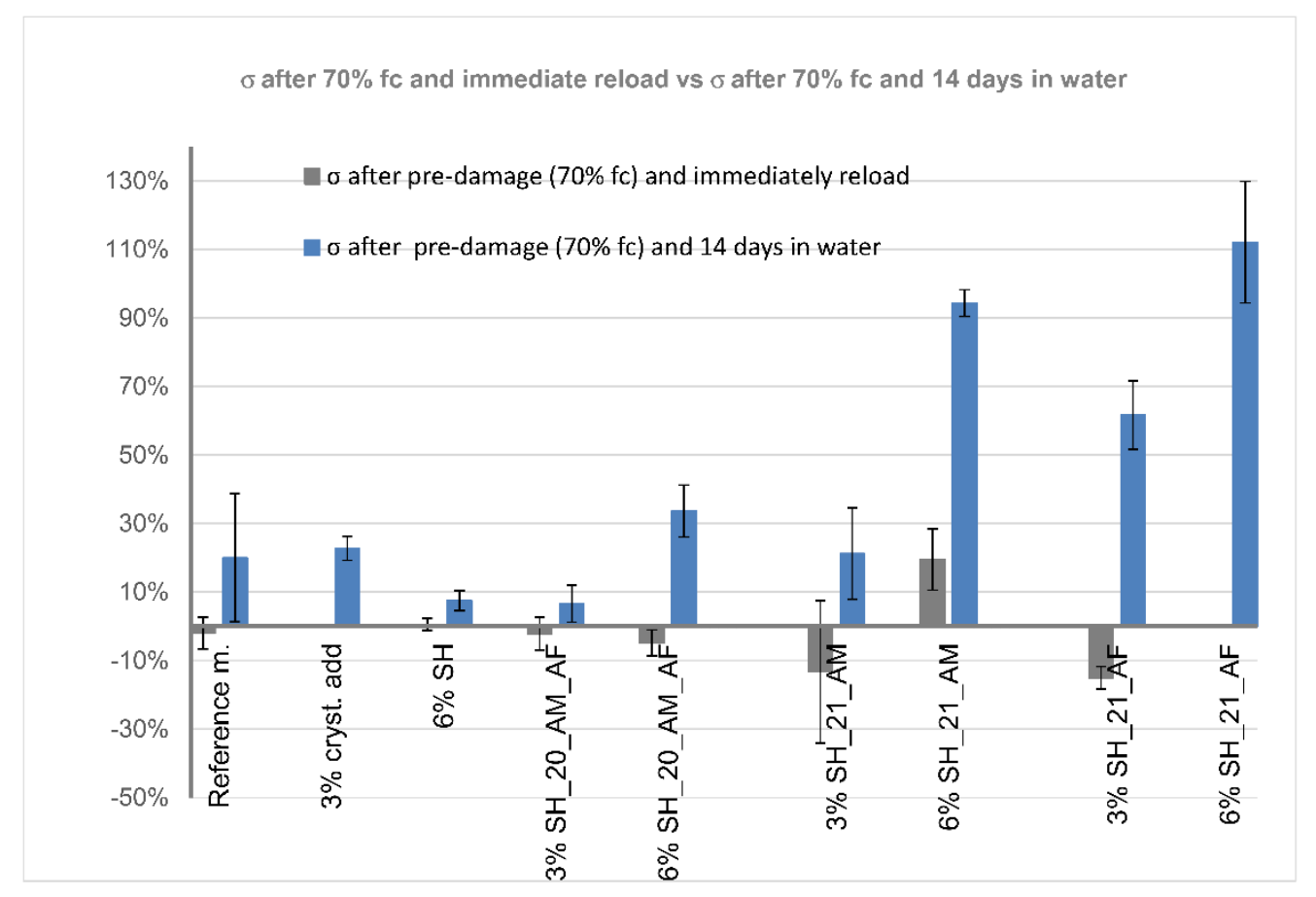

Fig 1 Microcapsules results: strength reloaded after pre-crack vs strength reloaded after curing time 


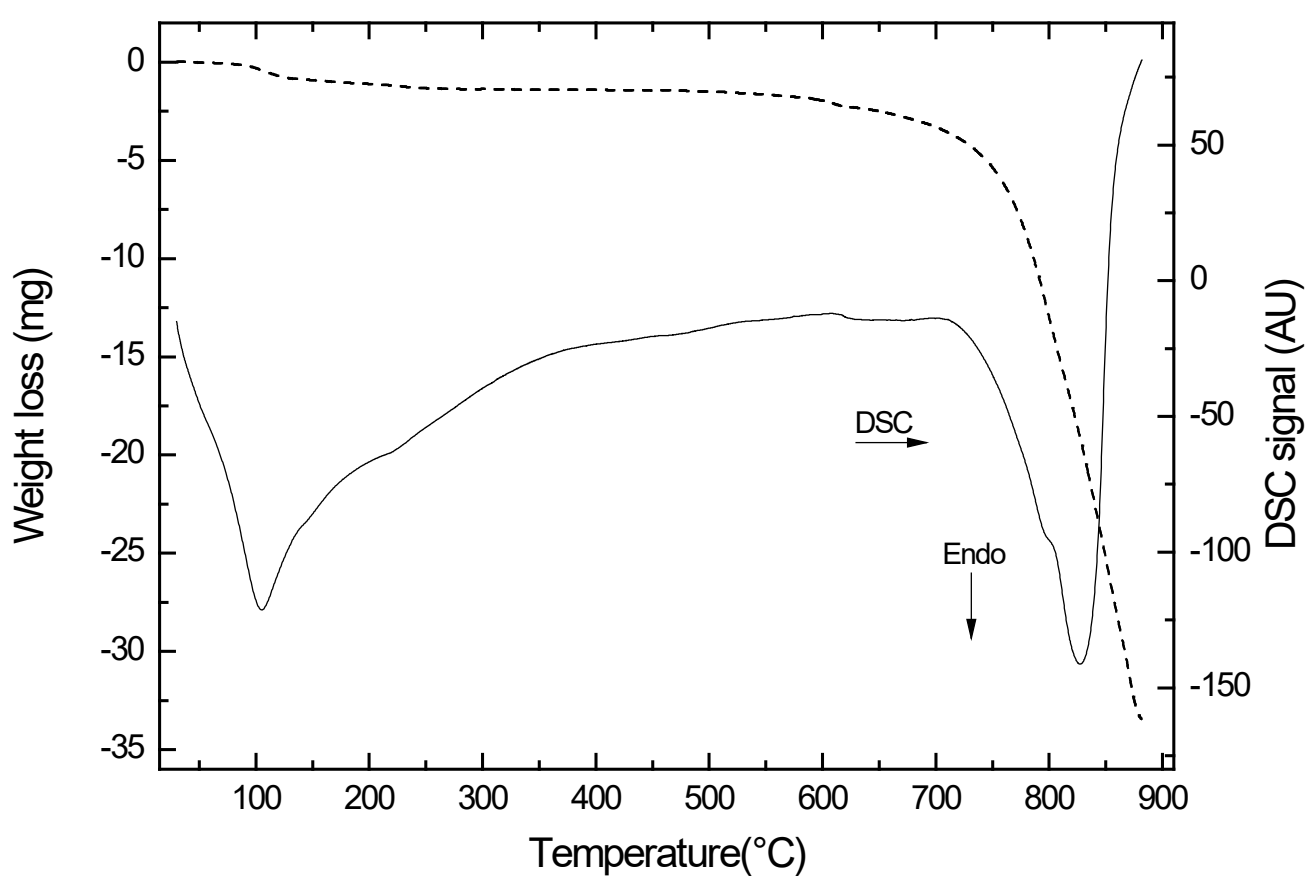

(a)

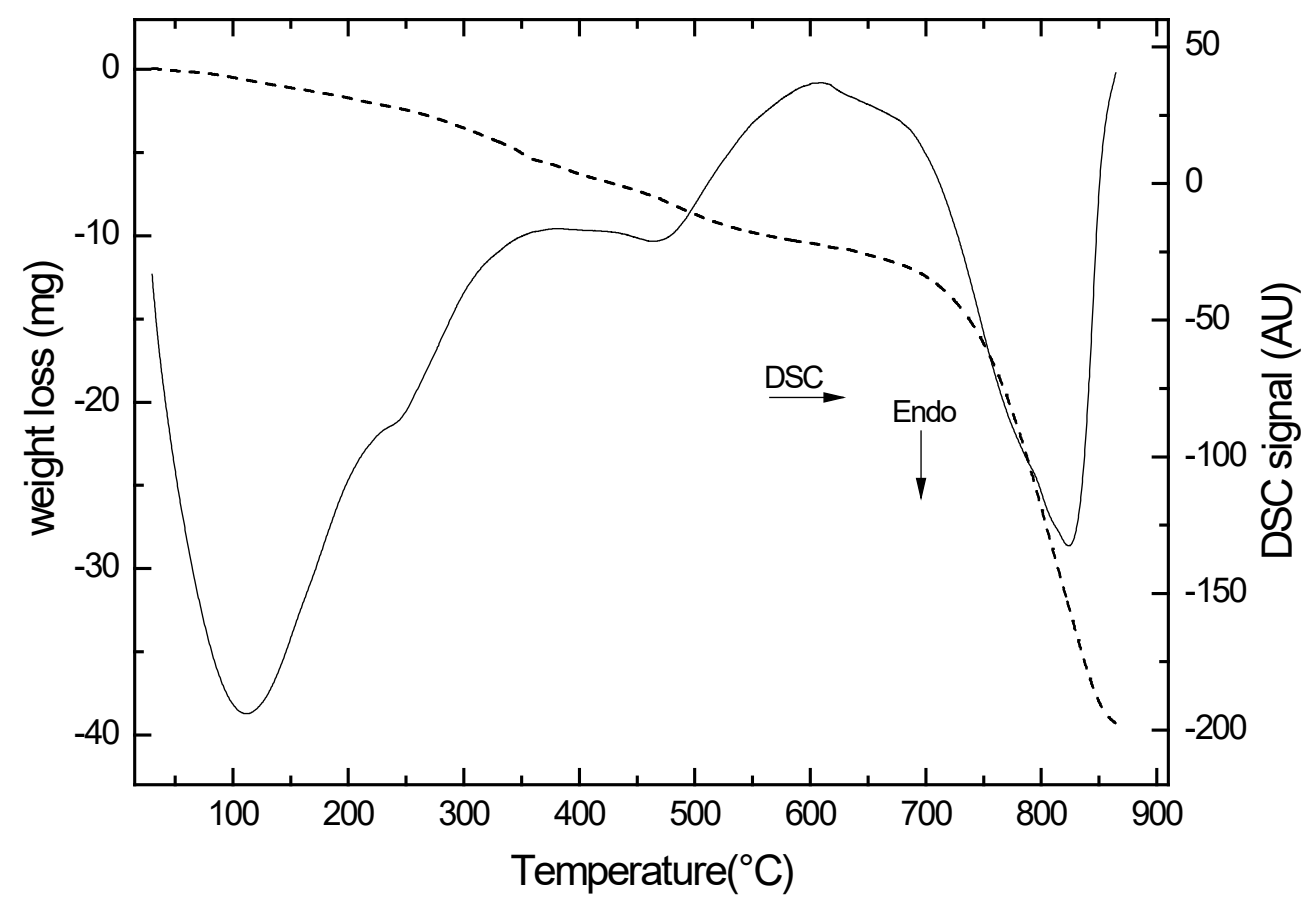

(b)

Fig. 2 TGA/DSC measurements: (a) lime-based mortar, (b) lime-based mortar plus NHL5_AM_AF at 6\% Run conditions (a) $65.12 \mathrm{mg}$, (b) $72.31 \mathrm{mg}$ heating rate $20^{\circ} \mathrm{C} / \mathrm{min}$.

(possiamo aggiungere sotto I picchi la sostanza che sta decomponendo a quella temperatura - water desorption sotto $1100^{\circ} \mathrm{C}$ e decarbonation a $800^{\circ} \mathrm{C}$ ) 


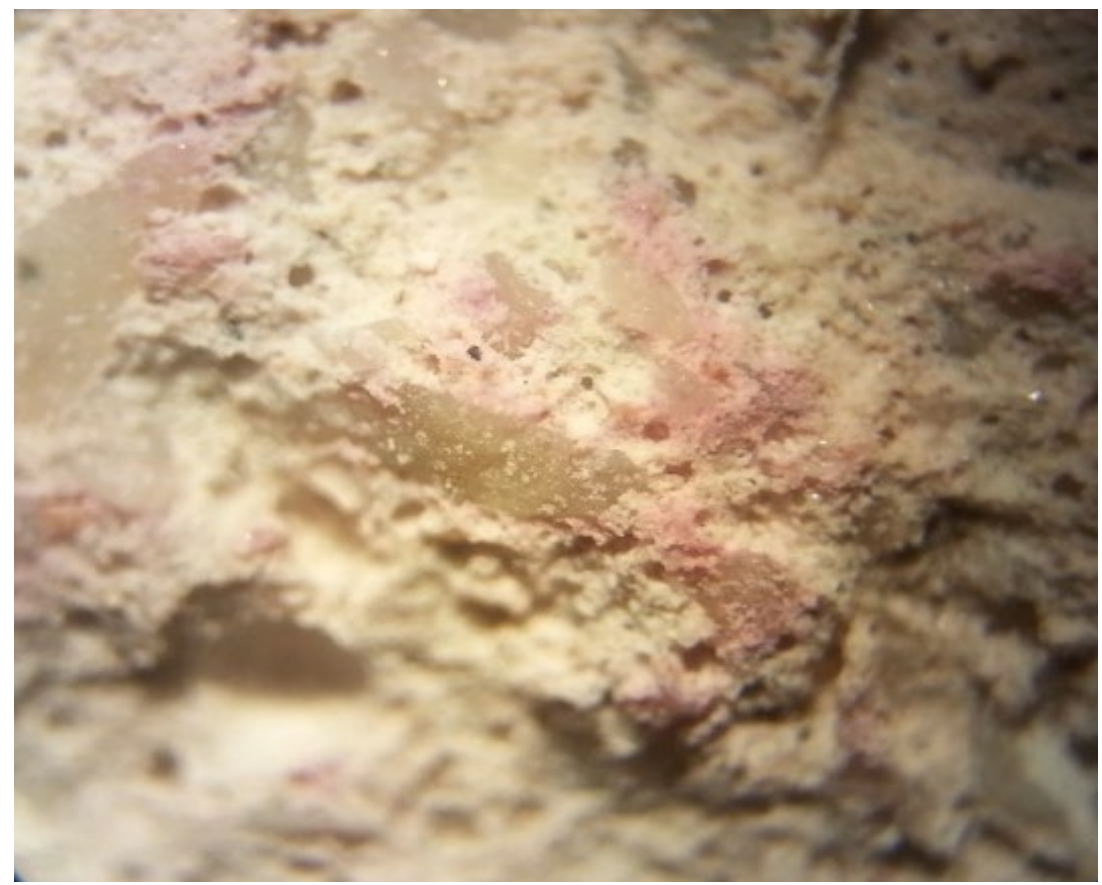

(a)

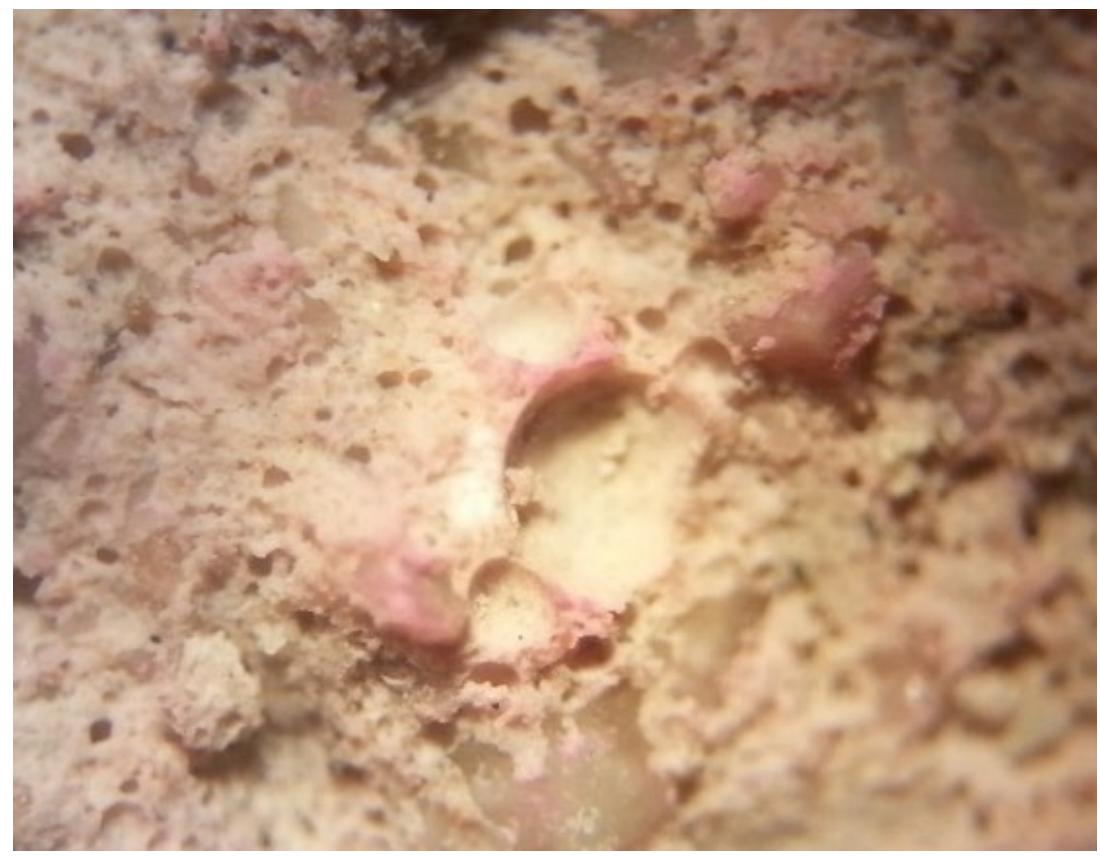

(b)

Fig 3. Phenolphthalein test adsorption: (a) NHL5 mortar; (b) NHL5 mortar plus NHL5_AM_AF at 6\% - larger and more uniformly distributed fucsia colored areas highlight the presence and uniform distribution of free $\mathrm{Ca}(\mathrm{OH}) 2$, as released upon capsule breakage. 


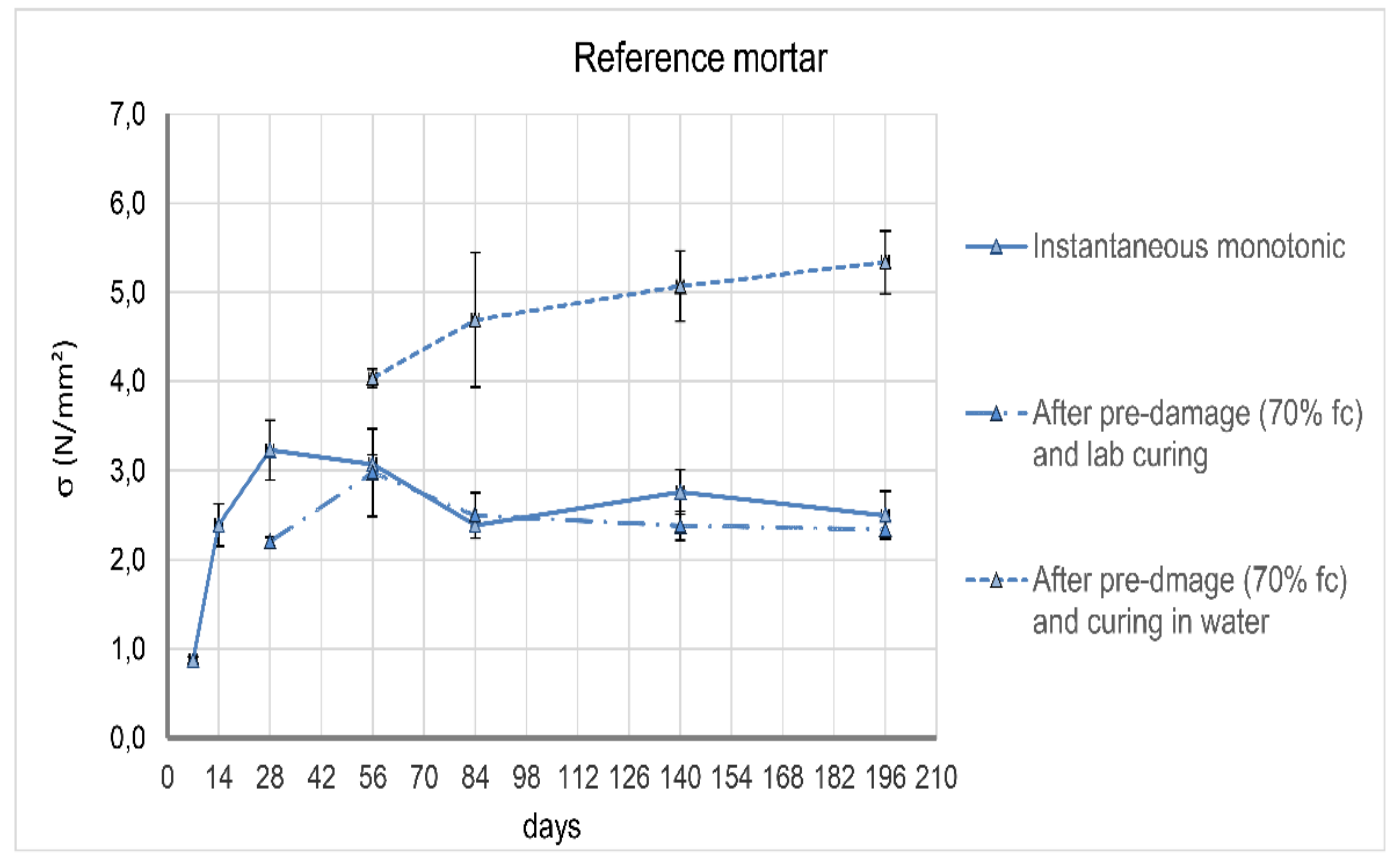

Fig. 4: Variation in compressive strength with age for reference mortar samples

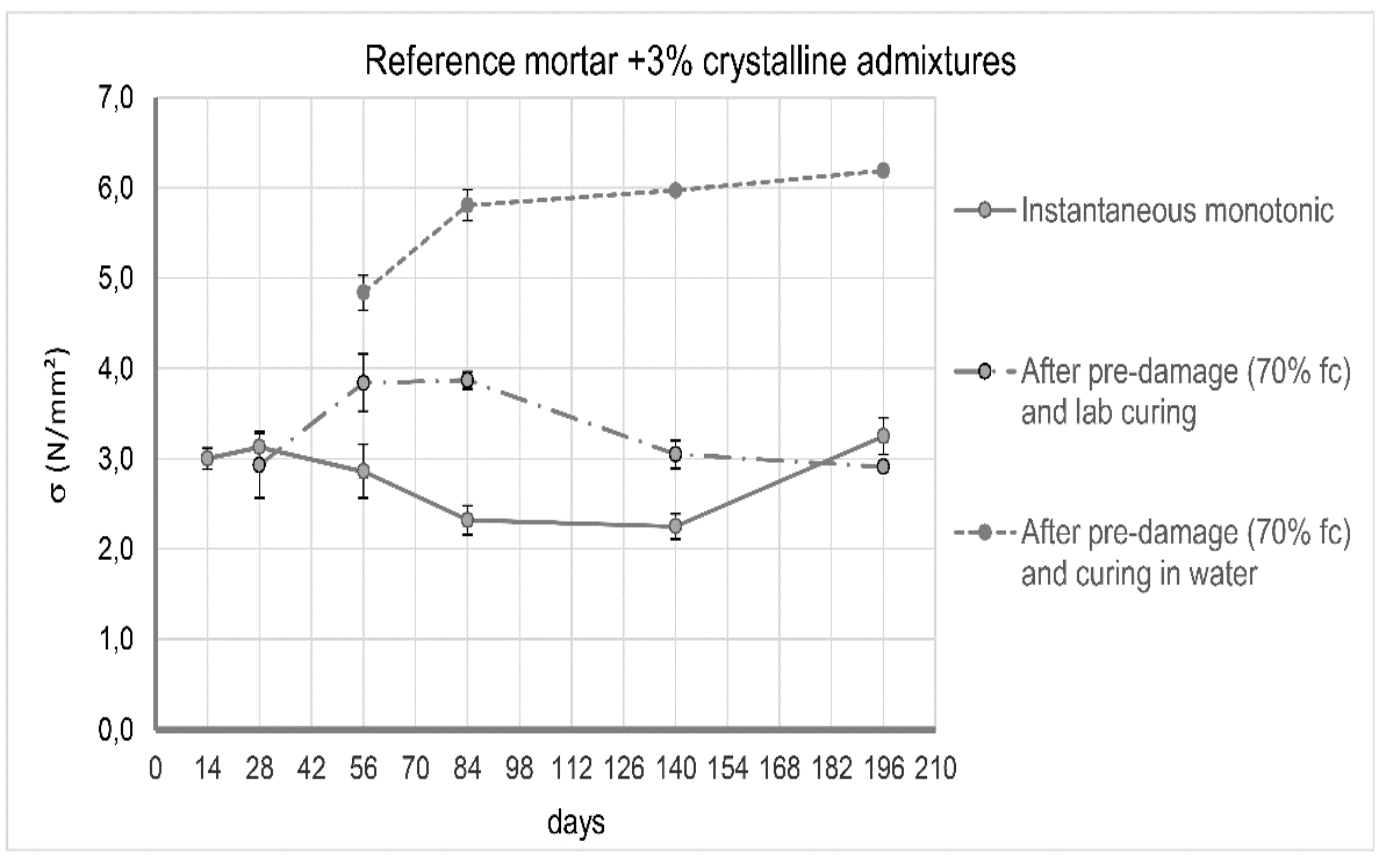

Fig. 5: Variation in compressive strength with age for reference mortar with crystalline additives samples 


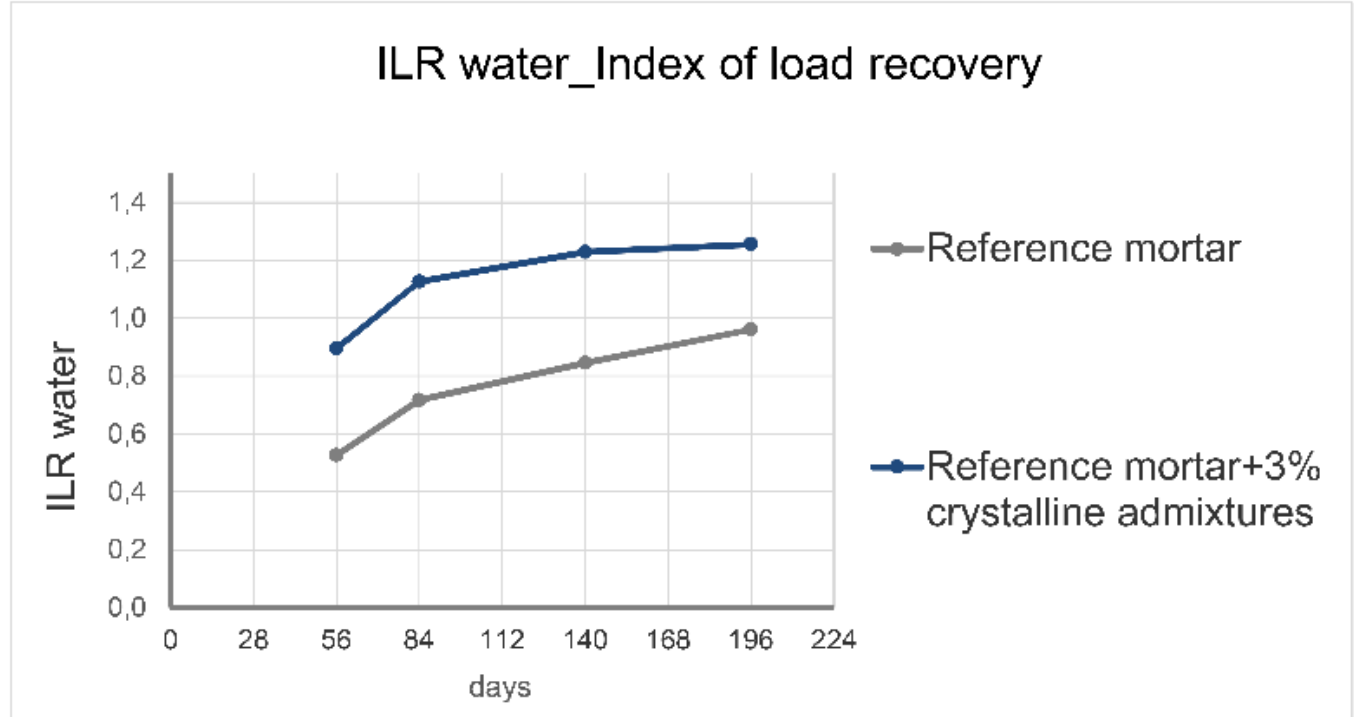

(a)

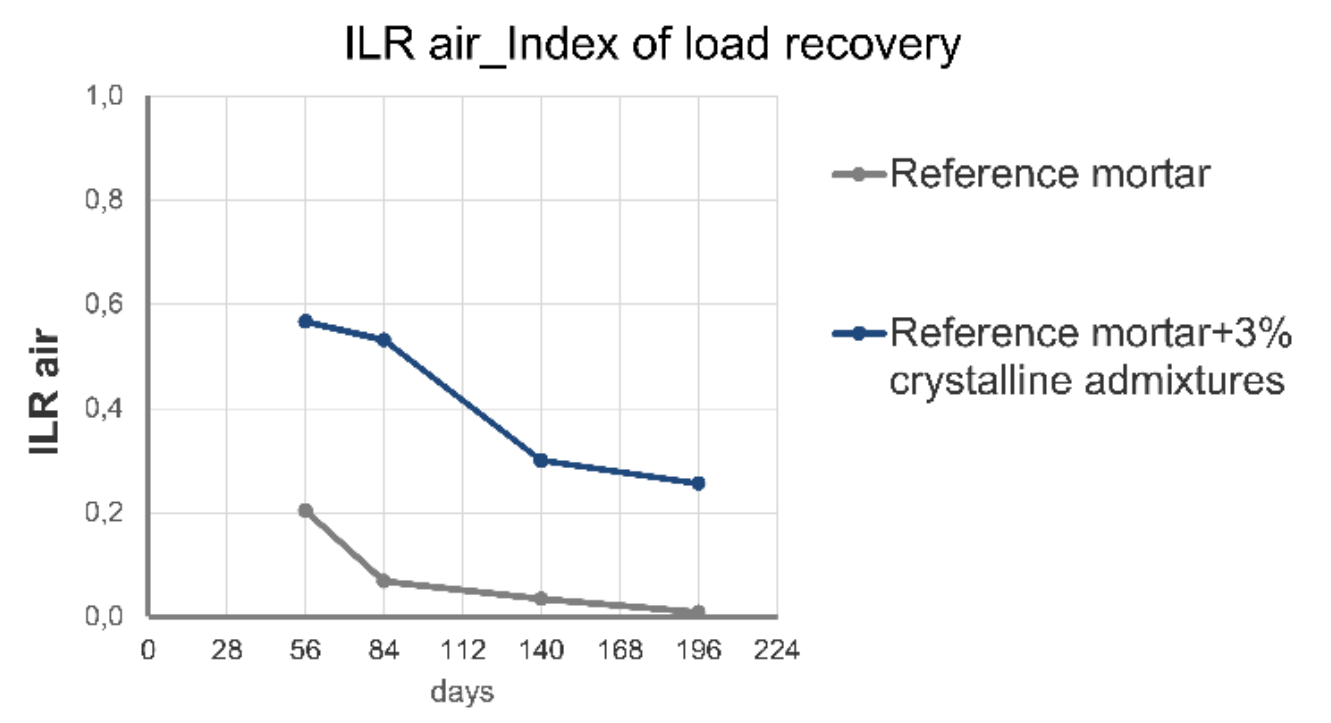

(b)

Fig. 6 shows the trend of ILR (a) water and ILR air (b) 